\title{
X-linked cerebral-cerebellar-coloboma syndrome
}

INSERM

\section{Source}

INSERM. (1999). Orphanet: an online rare disease and orphan drug data base. $\underline{X \text {-linked }}$ cerebral-cerebellar-coloboma syndrome. ORPHA:163961

X-linked cerebral-cerebellar-coloboma syndrome is a rare, genetic syndrome with a cerebellar malformation as major feature characterized by cerebellar vermis hypo- or aplasia, ventriculomegaly, agenesis of corpus callosum and abnormalities of the brainstem and cerebral cortex in association with ocular coloboma. Clinically, patients show hydrocephalus at birth, neonatal hypotonia with abnormal breathing pattern, ocular abnormalities with impaired vision, severe psychomotor delay, and seizures. 